\title{
Friction Characteristics of Machined Metal with Different Surface Morphologies
}

\author{
Hsin-Min Lee, ${ }^{1}$ A-Cheng Wang, ${ }^{2}$ and Yan-Cherng Lin ${ }^{3}$ \\ ${ }^{1}$ Department of Mechanical Engineering, Army Academy, Taoyuan 32093, Taiwan \\ ${ }^{2}$ Department of Mechanical Engineering, Chien Hsin University of Science and Technology, Taoyuan 32097, Taiwan \\ ${ }^{3}$ Department of Mechanical Engineering, Nan Kai University of Technology, Nantou 54243, Taiwan
}

Correspondence should be addressed to Hsin-Min Lee; 1sm5762@gmail.com

Received 4 October 2014; Accepted 27 January 2015

Academic Editor: Allan C. Peterson

Copyright (C) 2015 Hsin-Min Lee et al. This is an open access article distributed under the Creative Commons Attribution License, which permits unrestricted use, distribution, and reproduction in any medium, provided the original work is properly cited.

\begin{abstract}
This study examined the friction characteristics of SAE1045 medium carbon steel processed by milling machining (MM) and abrasive jet machining (AJM). Friction experiments were conducted with variations in load and friction distance. Experimental results show that micro craters produced by AJM help retain lubricant on workpiece surface and thus decrease friction coefficient. Consequently, for the same friction distance, the amount of wear on AJM test specimens is less than that of MM ones. Moreover, increase in load and surface roughness will also result in great wear on the test specimens.
\end{abstract}

\section{Introduction}

Abrasive jet machining (AJM) is to form on workpiece surface micro craters of different morphologies using highpressure gas injection. The machining characteristics of AJM are similar to the production of micropores in scraping process. These micropores serve to retain lubricants on the workpiece surface, which enables smooth sliding motion, thus contributing to lessen surface friction during machining and reducing machine wear.

During application of process technology, the machine tool is the key equipment. However, wearing of the sliding face between the loading table and slide rails often occurs. As a result, clearance is formed, creating vibration and motion of the loading table during machining, which undermines machining precision. To overcome such drawback, lubricants are provided to slow down and reduce wear of the sliding face, and the success of lubrication against wearing is dependent on the persistence of the lubricating film, friction coefficient of a material or surface, and wears resistance of the sliding face.

The literature contains plentiful studies on the effect of lubrication and its application. When lubricants are introduced, friction is reduced and surface damage processes are modified; in particular, an increase in lubricant viscosity was observed to increase wear depth [1]. Research on effects of lubrication on artificial implants has special significance because it would help to prevent wearing and loosening of implants and thus lengthen their service life [2]. Poor lubrication not only results in machine wear but also deteriorates machining accuracy. Consequently, the reliability and stability of the entire machining system will be undermined. Serious friction may even lead to damage of machine parts, which in turn increases production cost.

Much research effort has been devoted to enhancing lubrication effect and wear resistance of workpiece. One stream of research emphasizes workpiece surface modification through methods such as diamond-like coatings (DLC) [3], gas nitriding [4], ion nitriding [5], plasma nitriding [6], nitrogen ion implantation [7], plasma nitrocarburizing [8], physical vapor deposition (PVD), and chemical vapor deposition (CVD). These approaches often form a hard and brittle compound layer on the workpiece surface that has to be polished so as to achieve wear reduction. However, smooth polished surfaces cannot retain lubricants, which in turn undermine the effects of lubrication against friction, resulting in friction-induced wear. Another stream of research focuses on incorporating additives such as aluminum nitride (AlN) 


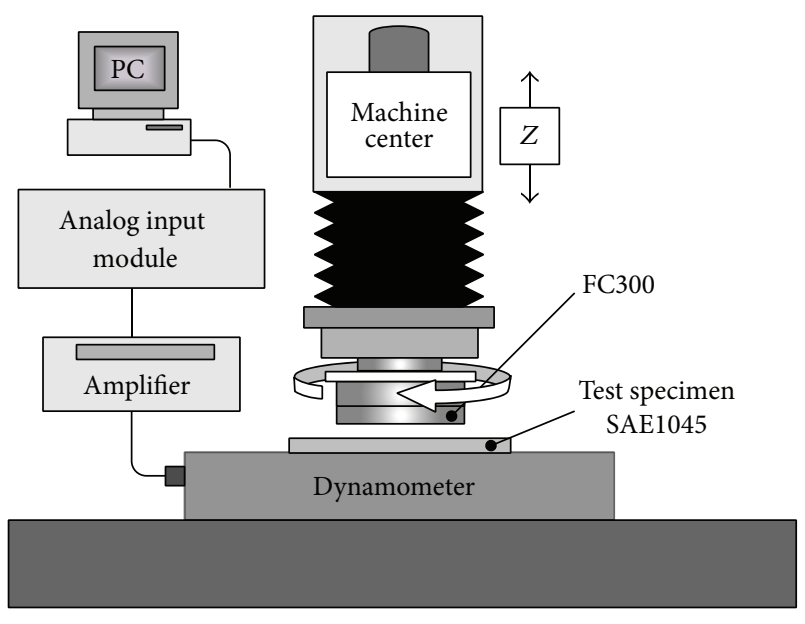

FIGURE 1: Schematic diagram of experimental setup.

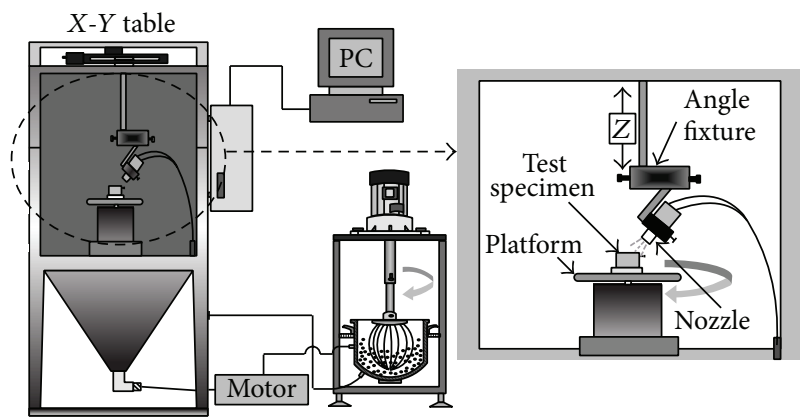

FIgURE 2: Abrasive jet machining (AJM) system.

[9], $\mathrm{TiO}_{2}$ [10], $\mathrm{ZnS}$ [11], and $\mathrm{Cu}$ [12]. Although satisfactory results on enhancement of lubrication and wear resistance are obtained, not only will failure to retain them on the workpiece surface affect the lubrication effect and wear reduction efficiency, but also their continuous and rapid loss will cause pollution to the environment.

In view of the above, industries currently using scraping process seek to increase the formation of micro craters on workpiece surface for retaining the lubricant and decreasing its loss, which in turn also reduces the friction coefficient and enhances the lubrication effect. However, very high manual operation cost is incurred which affects product competitiveness. Hence, AJM which can form micro craters on workpiece surface by high-pressure gas injection of abrasives is considered. Nevertheless, AJM has been applied mainly to atomization of workpiece surface and burr removal in industries. Prior academic investigations on AJM mainly examined quality of craters on hard and brittle compound material $[13,14]$ and there has been no research yet on the lubricant storage in micro craters on AJMed workpiece surface. In this study, test specimens are prepared using AJM and milling machining (MM) and experiments are conducted examining the storage of lubricant in the micro craters thus formed and their contribution to lubrication against friction.
TABLE 1: Parameters of friction experiment.

\begin{tabular}{lc}
\hline Load $(\mathrm{MPa})$ & $0.5,2.0$ \\
Slide speed $(\mathrm{m} / \mathrm{min})$ & 30 \\
Friction distance $(\mathrm{m})$ & 100,1000 \\
Lubricant $(\mathrm{cc})$ & 0.2 \\
\hline
\end{tabular}

TABLE 2: Mechanical properties of SAE1045 medium carbon steel.

\begin{tabular}{lc}
\hline Tensile strength $\left(\mathrm{kg} / \mathrm{mm}^{2}\right)$ & 58 \\
Compressive strength $\left(\mathrm{kg} / \mathrm{mm}^{2}\right)$ & $58-72$ \\
Hardness $(\mathrm{HB})$ & $201-269$ \\
\hline
\end{tabular}

TABLE 3: Machining methods and surface roughness of test specimens.

\begin{tabular}{lcclc}
\hline Test specimen & AJM1 & AJM2 & MM1 & MM2 \\
Machining method & Abrasive jet machining & Milling machining \\
Roughness Ra $(\mu \mathrm{m})$ & 1.66 & 6.24 & 1.61 & 6.36 \\
\hline
\end{tabular}

\section{Experimental Design}

2.1. Friction Test. Figure 1 is the schematic diagram of the experimental setup. The friction experiment was conducted according to the ASTM D 3702-94 standard using the parameters shown in Table 1. In the experiment, the triaxial component was measured by a piezoelectric dynamometer (Kistler 9257B, Germany). The measurements made were then transmitted by a multichannel charge amplifier (Kistler 5019A, Germany) to the analog input module (NI9215, USA). With the information extracted, the friction coefficient was calculated by the computer using the Lab View program.

2.2. Preparation of Test Specimens and Measurement Process. The friction test specimens were made from SAE1045 medium carbon steel, whose mechanical properties are shown in Table 2. Test specimens of different surface roughness were prepared by both AJM and MM. AJM was performed using the self-developed AJM system, shown in Figure 2, which was modified from the traditional sand blaster, while MM was conducted using the FMC-1000 CNC Machine Center (Fulland, Taiwan). The abrasives used were oxidized aluminum powder $\left(\mathrm{Al}_{2} \mathrm{O}_{3}\right)$, with average particle size of $710 \mu \mathrm{m}$. Table 3 lists the surface roughness of test specimens prepared by both methods.

Prior to measurements being made, all test specimens had their impurities removed by an ultrasonic cleaner. Surface roughness was measured by a contact-based surface roughness tester (Surfcom 130A, Japan); surface morphology was observed by both scanning electron microscope (SEM) (S3500 N, Hitachi, Japan) and atomic force microscopy (AFM) (Kosaka Laboratory SEF-3500K, Japan).

\section{Results and Discussion}

3.1. Effects of Surface Morphology on Friction Coefficient. Figure 3 shows the changes in friction coefficients with surface morphology and load. As can be seen from different 


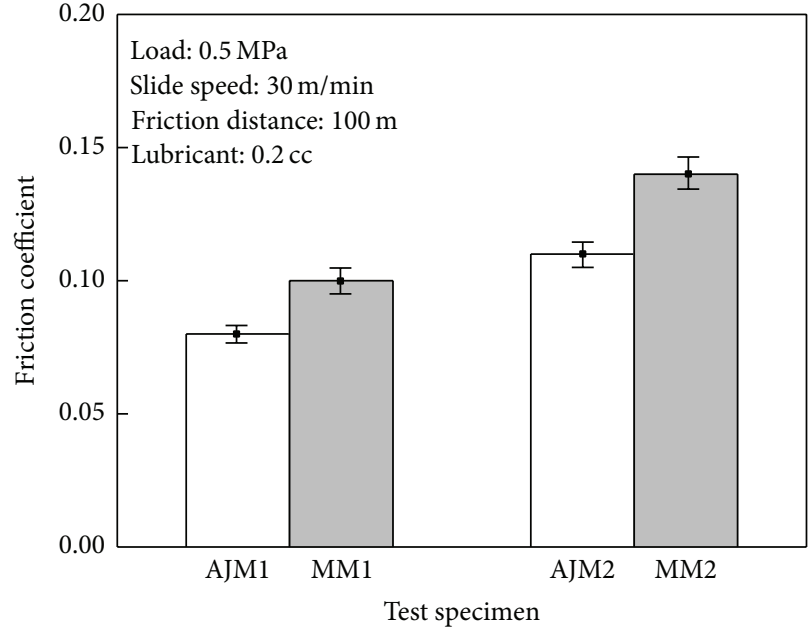

(a)

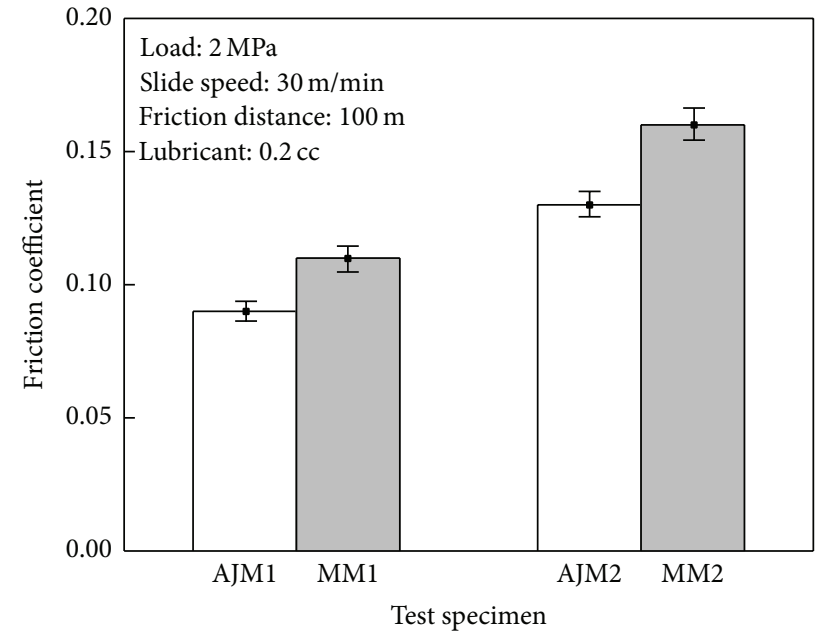

(b)

FIgURE 3: Relationship between the shapes of machined surfaces and friction coefficients under the load of (a) $0.5 \mathrm{MPa}$, (b) $2 \mathrm{MPa}$.

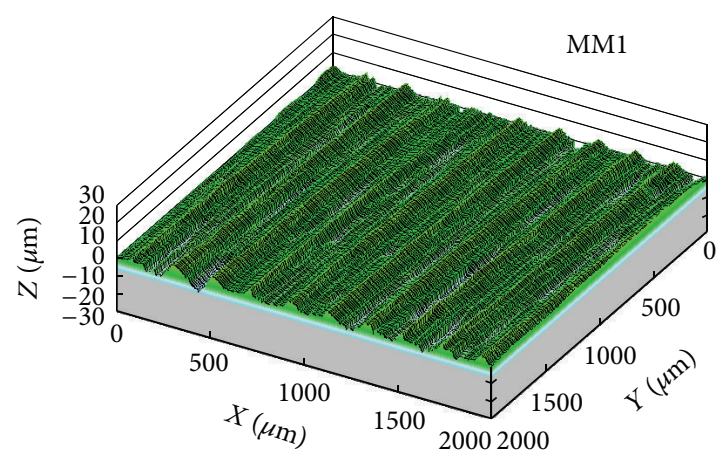

(a)

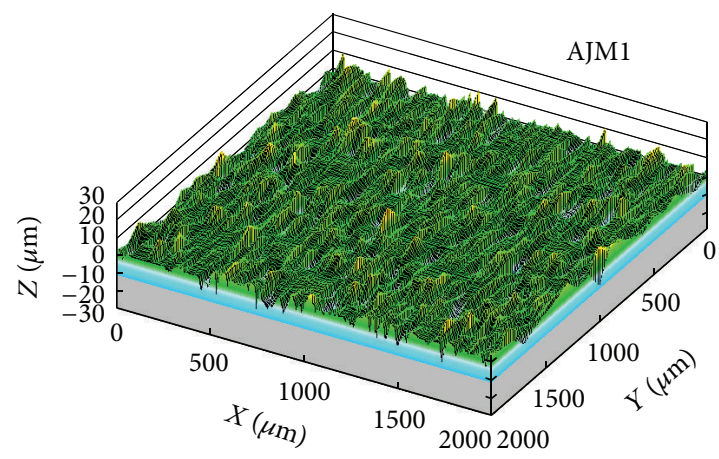

(c)

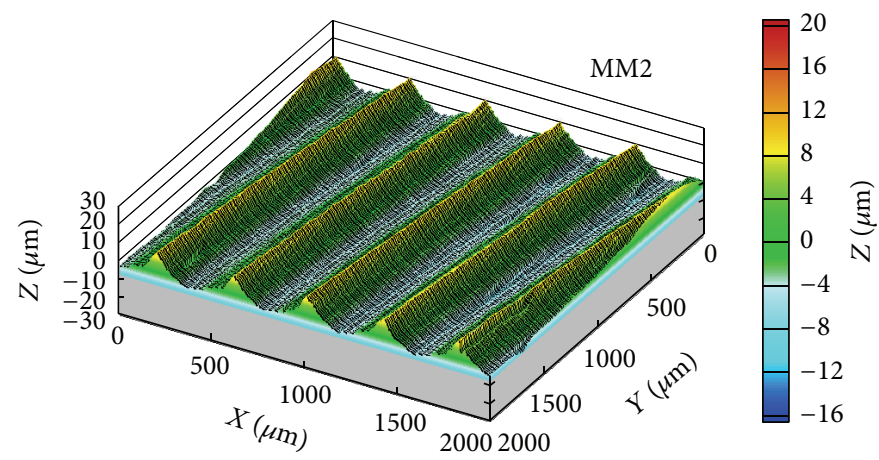

(b)

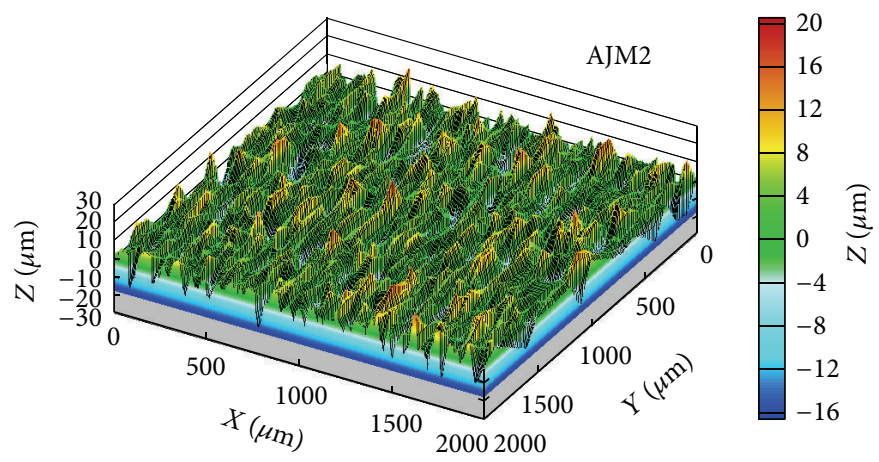

(d)

FIGURE 4: 3D profiles of surface morphology of test specimens.

machining ways, different shapes may be produced on test specimen surfaces. For the part of MM, obvious tool marks are found on the machined surfaces; and for the part of AJM, many micro craters are formed on the machined surfaces.

Figure 4 shows the AFM-observed 3D surface morphology on test specimens after AJM and MM, revealing variations in surface morphology on specimens produced by different methods. As seen in Figures 4(a) and 4(b), obvious tool marks are found on the surfaces prepared by MM, while many micro craters are formed on the AJMed surfaces, as seen in Figures 4(c) and 4(d). As observed from the above, it can be clearly analyzed and understood that since a great deal 


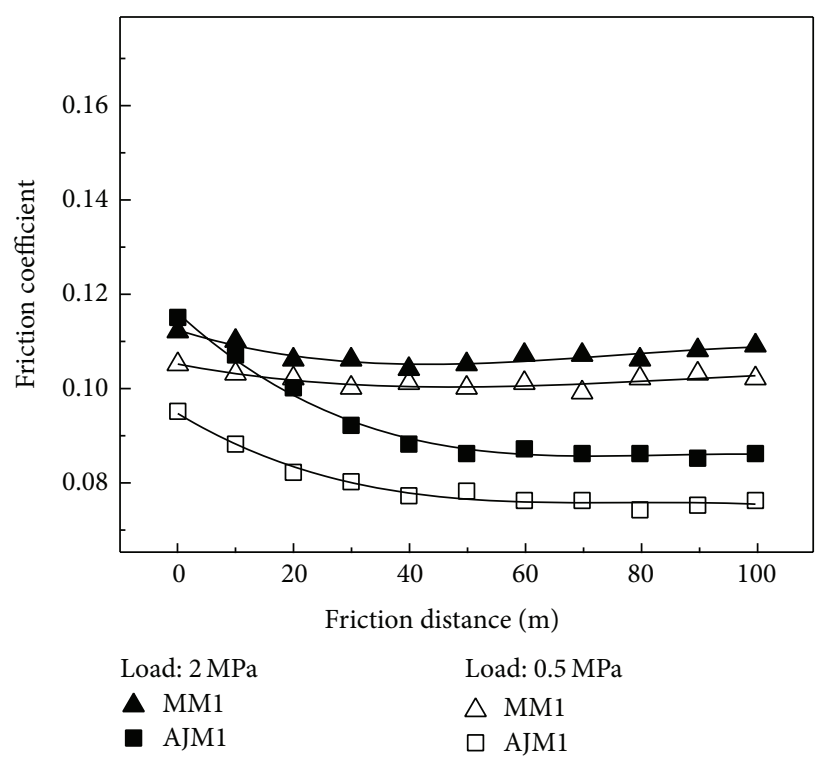

(a)

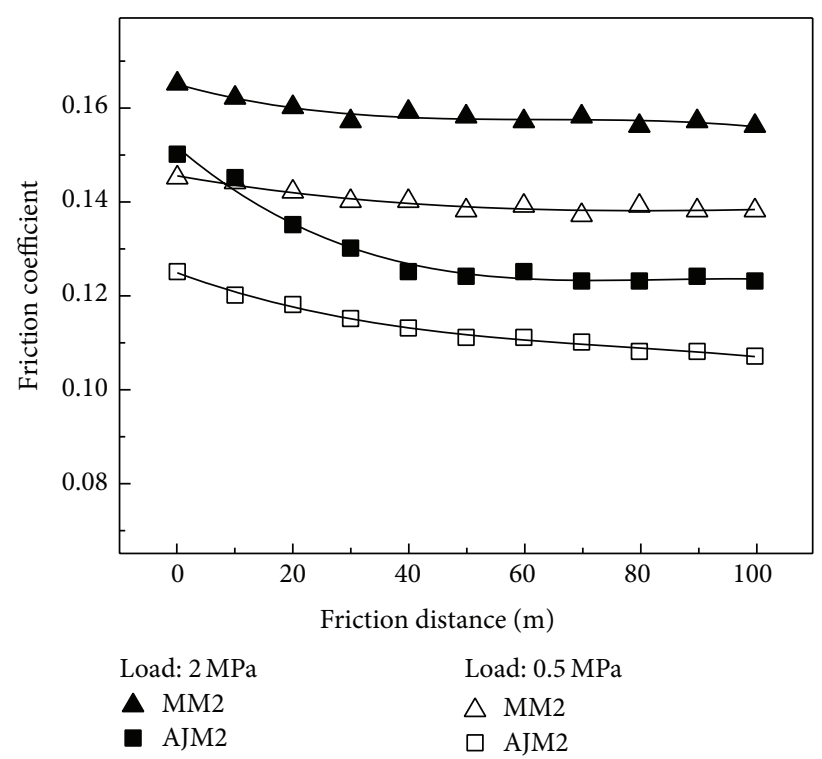

(b)

FIGURE 5: Relationship between different loads and friction coefficients.

of micro craters with oil storage function are produced on the test specimen surfaces having undergone AJM, lubricant cannot be easily lost in times of friction of test specimens, and lower friction coefficients are thus caused. Nevertheless, in the friction process after MM, lubricant easily diffuses and is lost along the tool marks produced on test specimen surfaces. Relatively, the friction coefficients rise.

3.2. Effects of Friction Distance on Friction Coefficient. Figure 5 shows the charts about how different friction distances and loads are related to the friction coefficients of AJM test specimen surfaces and MM test specimen surfaces. As clearly observed from the charts, under the same experimental conditions, the friction coefficients of $\mathrm{MM}$ test specimens have no obvious change with the increase of friction distance. Nevertheless, the friction coefficients of AJM test specimens gradually fall with the increase of friction distance. Comparing the friction coefficients of these two kinds of test specimens, it can be found that the friction coefficients of MM test specimens are obviously higher than those of AJM test specimens. Furthermore, it can be observed that, with the increase of load and surface roughness, the friction coefficients of the test specimen surfaces with two different machining ways are relatively increased.

Having observed and made comparative analysis of the SEM images shown in Figures 5 and 6, we can understand that, in the friction process at initial distance, the friction coefficients of MM test specimen surfaces are slightly reduced due to the action of lubricant. However, with the increase of friction distance, the tool marks on test specimen surfaces become flat and polished gradually due to friction effect. This is disadvantageous to the storage of lubricant and leads to the loss of lubricant and reduction of lubrication effect on the MM test specimen surfaces. Despite this, the friction coefficient is not obviously changed. As to the part of AJM test specimens, since friction occurs at the peak points of micro craters in contact mode in the initial friction process, higher friction coefficients are produced. Nevertheless, as these peak points are gradually abraded flat, and at the same time the lubricant stored in the micro craters undergoes lubrication effect, the friction coefficients on test specimen surfaces can be effectively reduced in friction process. When friction process reaches around $40 \mathrm{~m}$, since the peak wear at the micro craters is decreased, the friction coefficients tend to be stabilized gradually. On the other hand, due to the existence of micro craters on AJM test specimens, lubricant can be easily maintained to keep on lubricating. As a result, their friction coefficients are lower than those of MM test specimens.

From the process of friction experiment, it can also be inferred that, with the increase of load and surface roughness, the wear caused on test specimen surfaces is intensified, thus further increasing the friction coefficients of test specimen surfaces.

3.3. Effects of Load on Wear Amount. Figure 7 shows the change of wear amount after AJM test specimens and MM test specimens conduct wear experiment at the distances $100 \mathrm{~m}$ and $1000 \mathrm{~m}$ under different surface roughness and loads. Comparing the experimental data in the charts, it can be clearly observed that, with the increase of load and friction distance, the wear amounts of test specimens increase accordingly. Comparing from the charts the wear of test specimens having undergone two different machining methods, it is also clearly found that, under the same experimental friction conditions, after the friction experiment at friction distance $100 \mathrm{~m}$ is completed, the wear amounts of AJM test specimens are higher than those of MM test specimens. Nevertheless, after the friction experiment at friction distance $1000 \mathrm{~m}$ is 


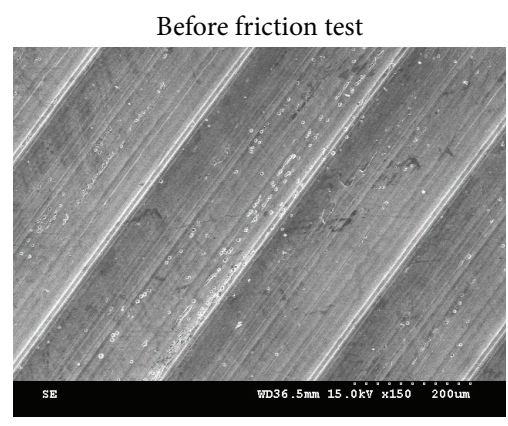

(a)

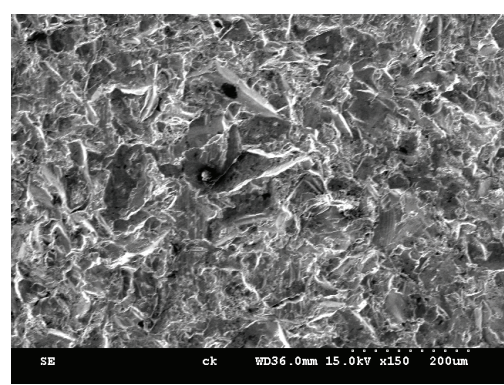

(d)
Friction load: $0.5 \mathrm{MPa}$

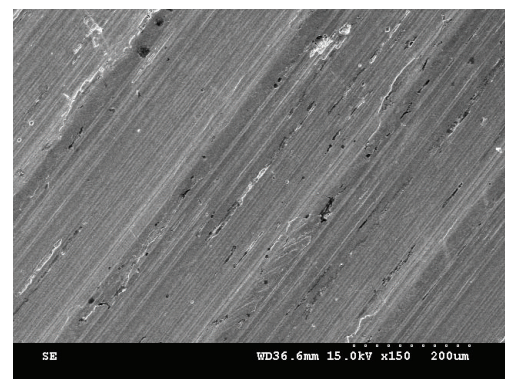

(b)

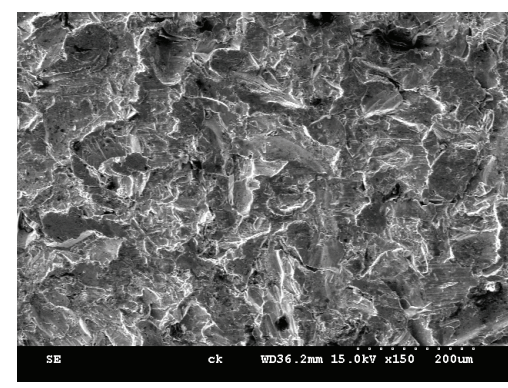

(e)

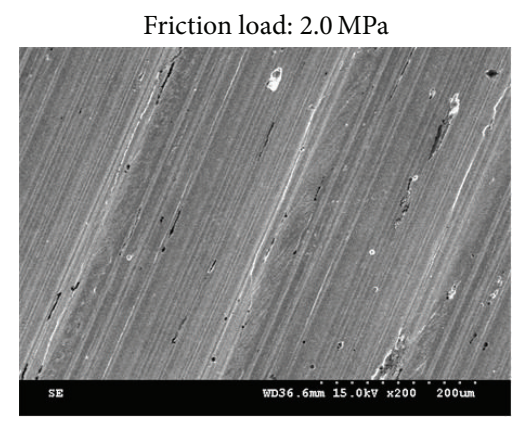

(c)

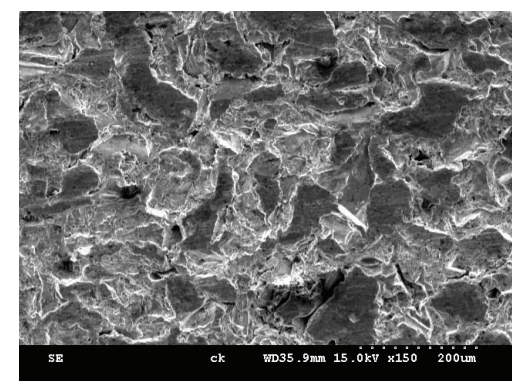

(f)

Figure 6: SEM images of test specimens (a)-(c) MM1, (d)-(f) AJM1, at friction distance $100 \mathrm{~m}$.

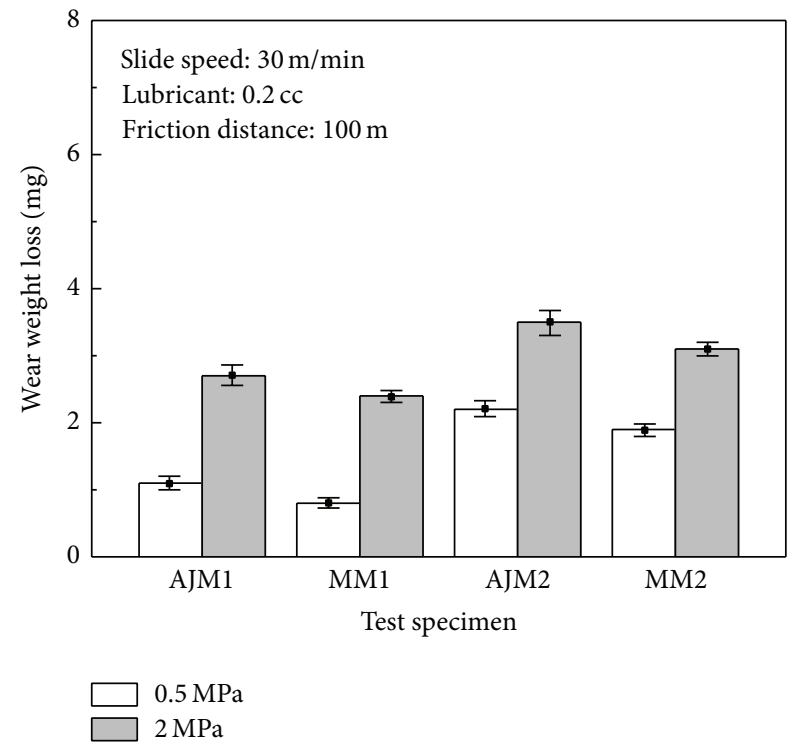

(a)

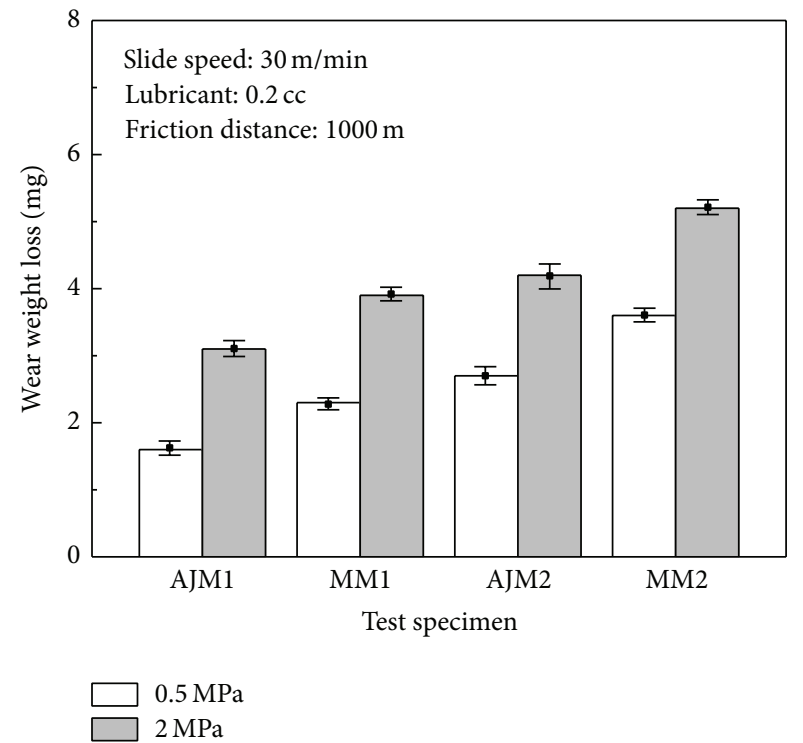

(b)

FIgURE 7: Comparison of loads and wear amounts under friction distances (a) $100 \mathrm{~m}$, (b) $1000 \mathrm{~m}$.

completed, the wear amounts of MM test specimens are higher than those of AJM test specimens.

The change of load causes obvious change in the wear amounts of both MM test specimens and AJM test specimens, as shown in Figures 7(a) and 7(b). Regarding the reason of such change, since high load can increase the friction force of test specimen and accelerate the wear of test specimen surface, greater wear amount is produced.
As observed from Figure 7(a), since AJM is characterized by using impacts of abrasives on test specimen surfaces to achieve the purpose of material removal, many micro craters in irregular shapes are formed on test specimen surfaces. In the sliding and friction process at the initial friction distance $100 \mathrm{~m}$, wear occurs in the way of point contact at the peaks and valleys that form the micro craters, and small planes with extremely small unit area are produced, thus resulting 


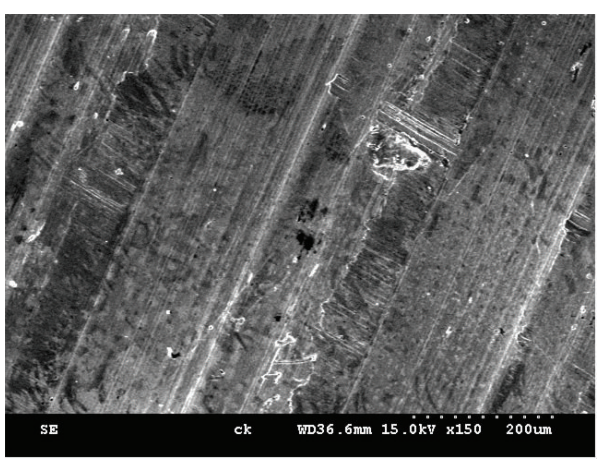

(a)

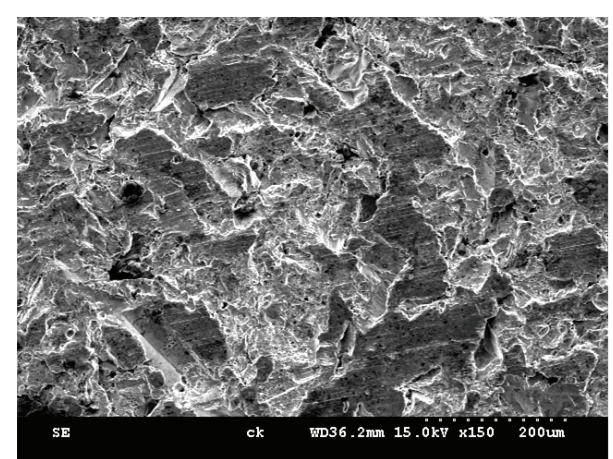

(b)

FIGURE 8: SEM images of test specimens (a) MM1, (b) AJM1, with load 2.0 MP and at friction distance $1000 \mathrm{~m}$.

in greater wear amount. As to the characteristics of MM test specimen, cutting tool is used to remove material, so tool mark shapes are produced on test specimen surface. In the friction process at the initial friction distance $100 \mathrm{~m}$, as wear occurs in the way of linear contact, the wear amount is lower.

When friction distance increases to $1000 \mathrm{~m}$, further observation and analysis of experimental results are made. As found in Figure 7(b), the wear amounts of MM test specimens are higher than the wear amounts of AJM test specimens. Regarding the reason for the occurrence of this phenomenon, it is inferred that, due to the slow area increase of the small planes formed at the peaks of AJM test specimen surfaces as well as the continuous supplementation of lubricant in micro craters, the wear increase rate can be effectively reduced. However, as to the wear situation of MM test specimens, since it is not easy to keep lubricant staying in the tool marks on test specimen surfaces, lubricant is lost continuously in the friction process, leading to the occurrence of viscous wear. Therefore, their wear amounts are higher than the wear amounts of AJM test specimens, as shown in Figure 8.

\section{Conclusion}

By the two machining ways of milling machining (MM) and abrasive jet machining (AJM), the study makes test specimens with different surface shapes and different roughness. Under different loads, the paper investigates the effects of friction distance on friction coefficient and wear and summarizes the experimental results as follows.

(1) Since the test specimen surfaces having undergone AJM have micro craters for oil storage, lower friction coefficients are produced. As the test specimen surfaces having undergone MM have tool marks formed, lubricant easily diffuses along the tool marks and is finally lost. Thus, the friction coefficients are relatively high.

(2) With the increase of friction distance, the friction coefficients of AJM test specimen surfaces gradually decrease, but the friction coefficients of MM test specimen surfaces have no obvious change. As the load and surface roughness are increased, the friction coefficients of test specimen surfaces having undergone two different machining ways are increased accordingly.

(3) In the wear experiment with friction distance $100 \mathrm{~m}$, the wear amounts of AJM test specimens are higher than those of MM test specimens. Nevertheless, in the wear experiment with friction distance $1000 \mathrm{~m}$, the wear amounts of MM test specimens are higher than those of AJM test specimens. With the increase of load and friction distance, the wear amounts of test specimens are relatively increased.

\section{Conflict of Interests}

The authors declare that there is no conflict of interests regarding the publication of this paper.

\section{References}

[1] M. Messaadi, G. Bouvard, J. Yang, and P. Kapsa, "Wear of sintered HSS under combined squeeze-sliding lubrication," Wear, vol. 301, no. 1-2, pp. 768-775, 2013.

[2] L. Mattei, F. D. Puccio, B. Piccigallo, and E. Ciulli, "Lubrication and wear modelling of artificial hip joints: a review," Tribology International, vol. 44, no. 5, pp. 532-549, 2011.

[3] W. Yue, C. Liu, Z. Fu, C. Wang, H. Huang, and J. Liu, "Effects of molybdenum dithiocarbamate and zinc dialkyl dithiophosphate additives on tribological behaviors of hydrogenated diamond-like carbon coatings," Materials \& Design, vol. 64, pp. 601-607, 2014.

[4] H. Li, Z. Cui, Z. Li, S. Zhu, and X. Yang, "Effect of gas nitriding treatment on cavitation erosion behavior of commercially pure $\mathrm{Ti}$ and Ti-6Al-4V alloy," Surface and Coatings Technology, vol. 221, pp. 29-36, 2013.

[5] J. Qian, K. Farokhzadeh, and A. Edrisy, "Ion nitriding of a near$\beta$ titanium alloy: microstructure and mechanical properties," Surface and Coatings Technology, vol. 258, pp. 134-141, 2014.

[6] M. B. Karamıs, K. Yıldızlı, and G. C. Aydın, "Sliding/rolling wear performance of plasma nitrided H11 hot working steel," Tribology International, vol. 51, pp. 18-24, 2012.

[7] Z.-B. Cai, G.-A. Zhang, Y.-K. Zhu, M.-X. Shen, L.-P. Wang, and M.-H. Zhu, “Torsional fretting wear of a biomedical Ti6Al7Nb 
alloy for nitrogen ion implantation in bovine serum," Tribology International, vol. 59, pp. 312-320, 2013.

[8] M. H. Sohi, M. Ebrahimi, A. Honarbakhsh Raouf, and F. Mahboubi, "Effect of plasma nitrocarburizing temperature on the wear behavior of AISI 4140 steel," Surface and Coatings Technology, vol. 205, pp. S84-S89, 2010.

[9] Y. Tao, B. Wang, and Y. Tai, "Preparation and investigation of nano-AlN lubricant with high performance," Materials Chemistry and Physics, vol. 147, no. 1-2, pp. 28-34, 2014.

[10] R. Krishna Sabareesh, N. Gobinath, V. Sajith, S. Das, and C. B. Sobhan, "Application of $\mathrm{TiO}_{2}$ nanoparticles as a lubricantadditive for vapor compression refrigeration systems-an experimental investigation," International Journal of Refrigeration, vol. 35, no. 7, pp. 1989-1996, 2012.

[11] J.-J. Kang, C.-B. Wang, H.-D. Wang, B.-S. Xu, J.-J. Liu, and G.L. Li, "Research on tribological behaviors of composite $\mathrm{Zn} / \mathrm{ZnS}$ coating under dry condition," Applied Surface Science, vol. 258, no. 6, pp. 1940-1943, 2012.

[12] B. S. Zhang, B. S. Xu, Y. Xu, F. Gao, P. J. Shi, and Y. X. $\mathrm{Wu}$, "CU nanoparticles effect on the tribological properties of hydrosilicate powders as lubricant additive for steelsteel contacts," Tribology International, vol. 44, no. 7-8, pp. 878-886, 2011.

[13] H. Nouraei, K. Kowsari, J. K. Spelt, and M. Papini, "Surface evolution models for abrasive slurry jet micro-machining of channels and holes in glass," Wear, vol. 309, no. 1-2, pp. 65-73, 2014.

[14] H. Nouraei, A. Wodoslawsky, M. Papini, and J. K. Spelt, “Characteristics of abrasive slurry jet micro-machining: a comparison with abrasive air jet micro-machining," Journal of Materials Processing Technology, vol. 213, no. 10, pp. 1711-1724, 2013. 

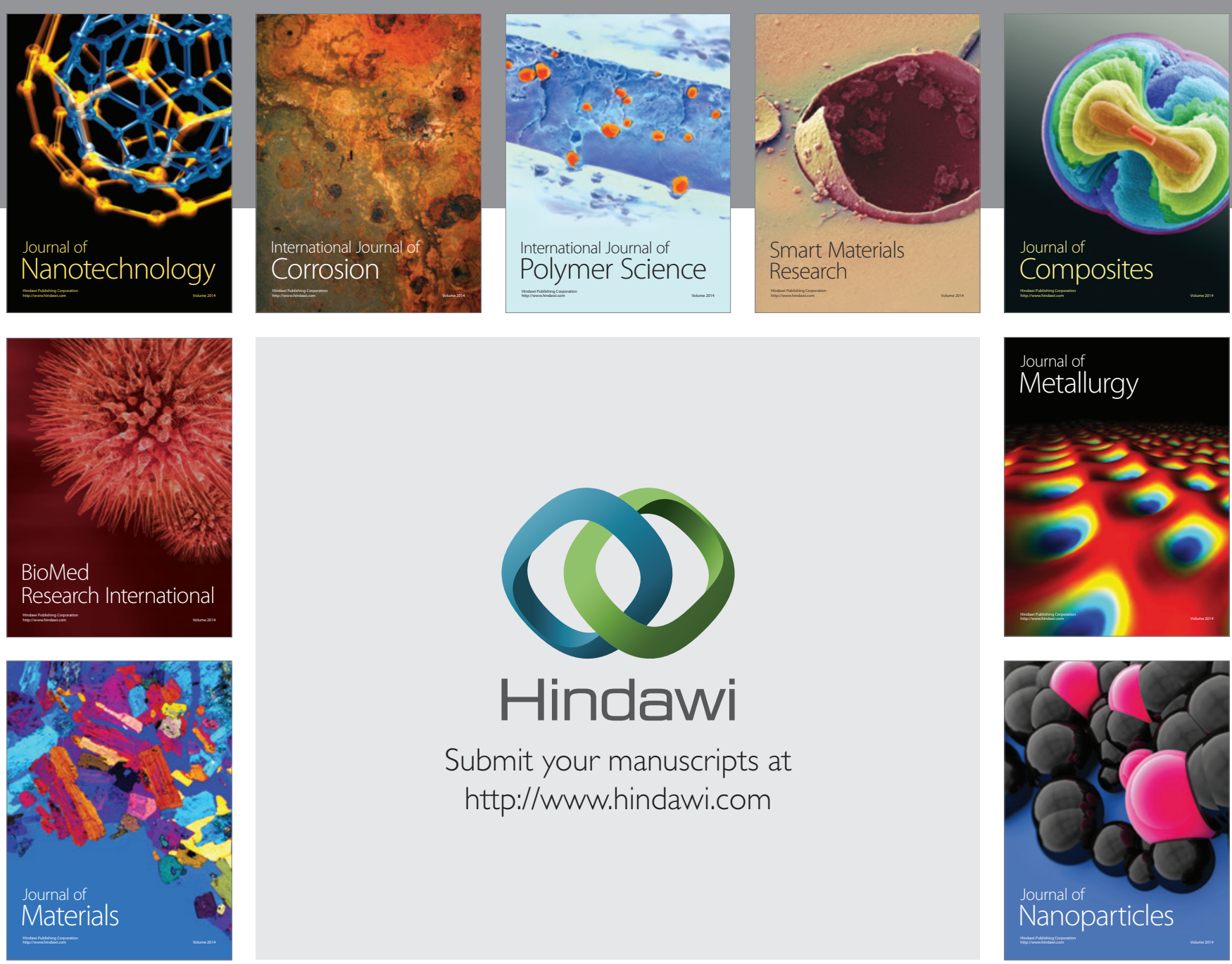

Submit your manuscripts at http://www.hindawi.com
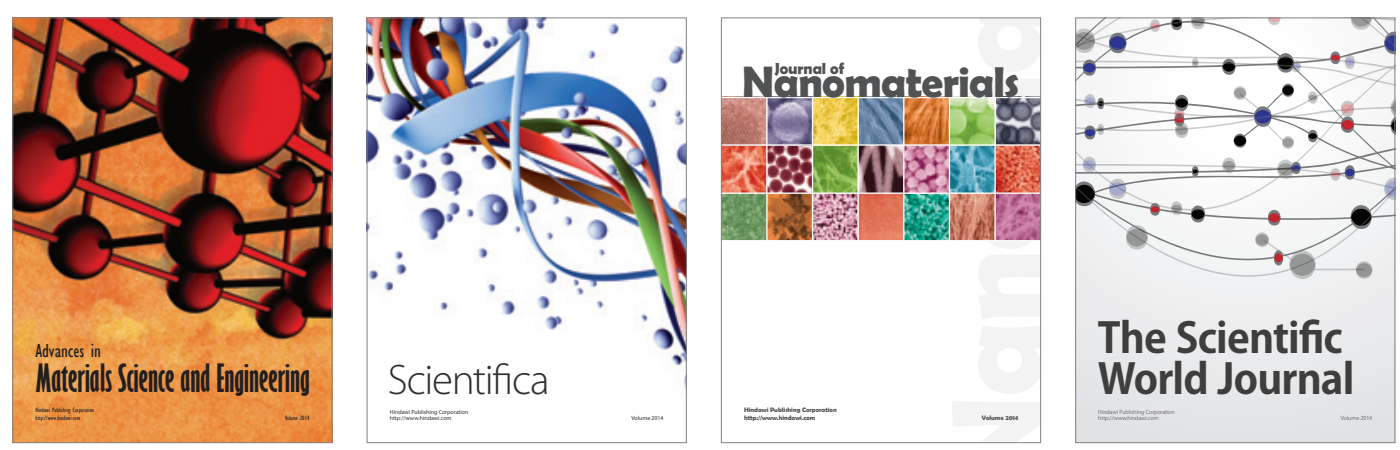

\section{The Scientific World Journal}
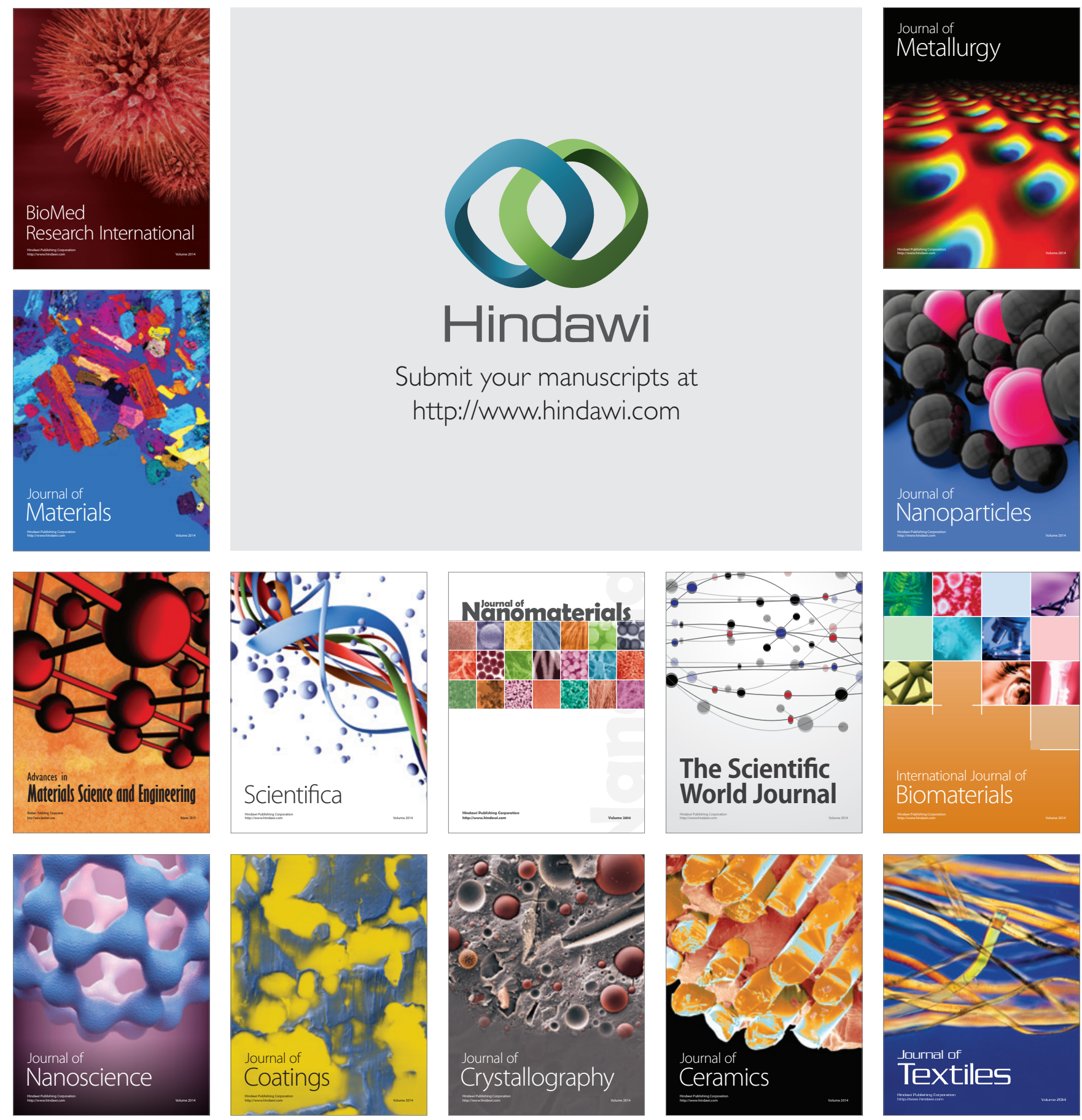